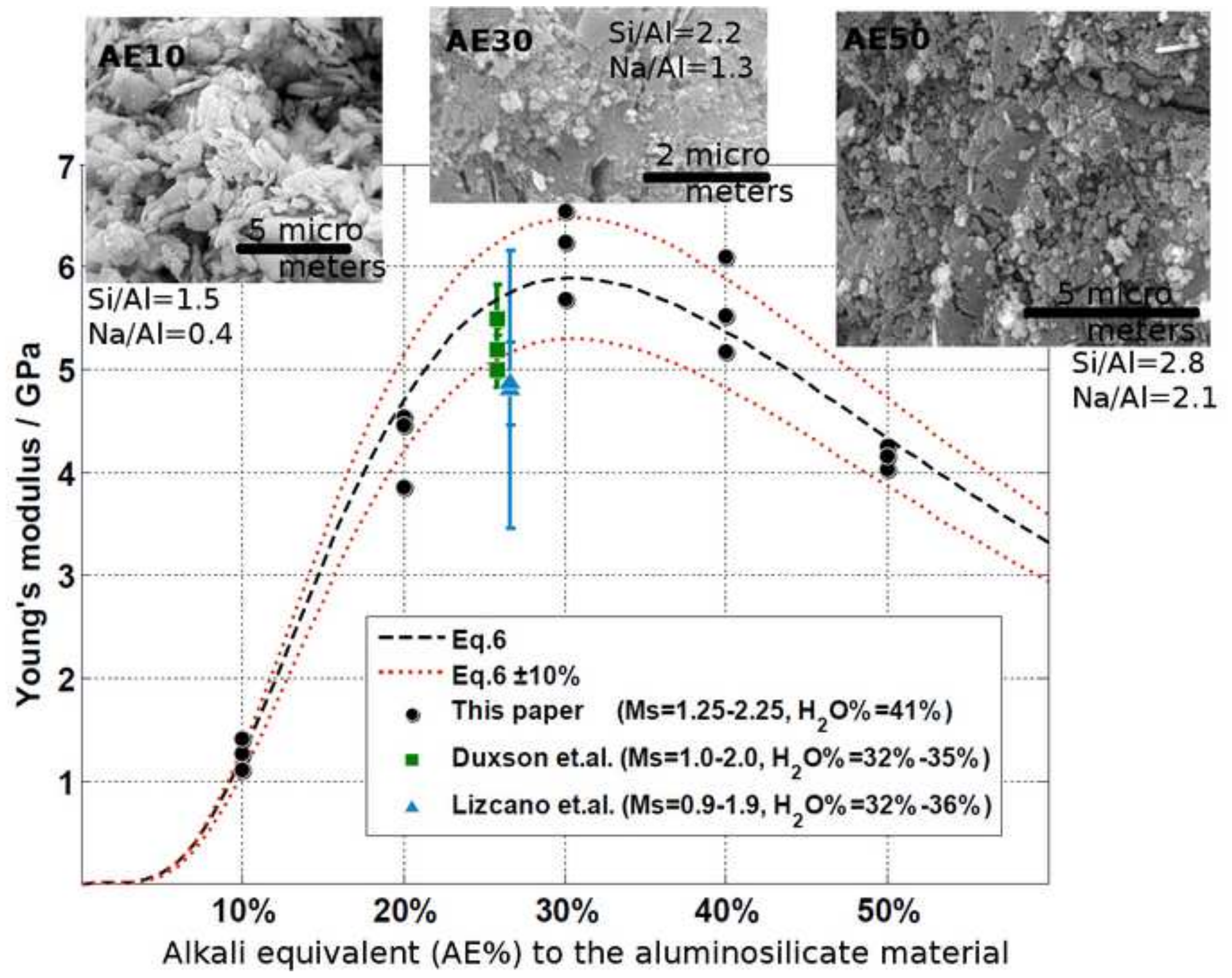




\section{Abstract}

\title{
Correlating the elastic properties of metakaolin-based geopolymer with its composition
}

\author{
Dongming Yan ${ }^{\mathrm{a}}$, Shikun Chen ${ }^{\mathrm{a}}$, Qiang Zeng ${ }^{\mathrm{a}, *}$, Shilang $\mathrm{Xu}^{\mathrm{a}}$, Hedong $\mathrm{Li}^{\mathrm{a}}$ \\ ${ }^{a}$ Institute of Advanced Structures and Materials, College of Civil Engineering and Architecture, Zhejiang University, Hangzhou, 310058, P.R.China
}

Geopolymer shows great potential as a construction material with low energy consumption and carbon oxide emission.

Quantitatively assessment of elastic properties of a geopolymer and understanding the correlations with its composition and microstructure are therefore very important for its rational utilization. In the present investigation, two series of metakaolin-based geopolymer (MKG) were synthesized by controlling, respectively, mass ratio of alkali in activator to powders, namely the alkali equivalent (AE) to the aluminosilicate materials, within a range of $10 \%-50 \%$ and molar ratio of $\mathrm{SiO}_{2}$ to $\mathrm{Na}_{2} \mathrm{O}$ in activator, namely modulus of silicate (Ms), within a range of $1.25-2.25$. General elastic mechanical properties (i.e., the Young's, bulk and shear moduli and the Poisson's ratio) of the MKG specimens were evaluated from load-strain curves measured by an integrated measurement and control system and the microstructures were determined by an ESEM-EDS analysis. The experimental results, combined with the analysis of variance method, indicate that, within the test ranges, the AE dosage influences all the characteristic elastic properties of the MKG specimens, whereas the effect of Ms level is insignificant. The morphology observations of the microstructures of the MKG specimens support the mechanical results, although both the AE dosage and Ms level change the chemical composition obviously. The results in the present study may help to tailor MKG material with its composition for further engineering applications.

Keywords: Geopolymer, Metakaolin, Microstructure, Elastic property.

\footnotetext{
${ }^{*}$ Corresponding author

Email address: cengq14@ z ju. edu.cn (Qiang Zeng)
} 


\section{Introduction}

Geopolymers are a class of hydrated aluminosilicate that can be synthesized by a geopolymerization reaction of aluminosilicate minerals (e.g. fly ash and metakaolin (MK)) with alkali activator solutions at ambient or higher temperature, and generally has cementing effect as binder materials [1-5]. Compared with ordinary Portland cement (OPC) that has been extensively used in civil and infrastructural engineering, geopolymer producing process has much lower energy consumption and $\mathrm{CO}_{2}$ emission [6-8] and the geopolymer-based materials possess outstanding resistance to corrosion, water absorption, sulfuric acid attack, thermal conduction and elevated temperature loads [2, 9.-16]. So, it has been regarded as a new and smart way for sustainable development and designs of new materials [1, 6, 8, 11]. To date, it has been developed many types of geopolymer-based materials that could be used in our daily lives, such as light weight concrete for construction and panel for decoration [17. 20], geopolymer foam for fire resistance [12, 21] and self-supporting inorganic membrane for water treatment [22].

The term "geopolymer" is based on the microstructure nature of these materials with macro amorphous structure and the coordination numbers of silicon and aluminum. The crystallite three dimensional structure is composed of $\mathrm{SiO}_{4}$ and $\mathrm{MAlO}_{4}$ tetrahedra, with $\mathrm{M}$ a monovalent cation (e.g. $\mathrm{Na}^{+}$or $\mathrm{K}^{+}$). This polymerized network is comparable to that of some zeolites but differs in its amorphous character. Because of the cross linking effect of the aluminum atoms on chains of the $\mathrm{SiO}_{4}$ tetrahedra, increasing the $\mathrm{Si} / \mathrm{Al}$ ratio tends to increase the polymeric character of these materials. The chemical formulation can be present in the form $\mathrm{M}^{+} \mathrm{n}\left[\left(\mathrm{SiO}_{2}\right) \mathrm{z}, \mathrm{AlO}_{2}\right] \mathrm{n}, \mathrm{wH}_{2} \mathrm{O}$, with $\mathrm{z}$ the $\mathrm{Si} / \mathrm{Al}$ molar ratio, $\mathrm{M}^{+}$is the monovalent cation and $\mathrm{n}$ is the polymerization degree [1, 3, 23]. Changing either the $\mathrm{Si} / \mathrm{Al}$ ratio or $\mathrm{Si} / \mathrm{M}$ ratio may allow the synthesis of materials with different structures. The chemical structure alteration, in return, may impact the macro mechanical properties of the materials.

Mechanical properties of geopolymer are of utmost importance for its engineering application. So extensive experimental investigations on the compressive and/or split strength of geopolymer paste, mortar and concrete have been conducted (e.g. [19, 20, 24, 29]). The parameter of strength only characterizes the maximum resistance against a type of load without further material information. Most structures, however, suffer limited loads during the entire service life, thus the materials are mostly in elastic state. Therefore, it still remains difficult to tailor or design geopolymer-type materials for engineering application due to the limited understandings on the elastic mechanical properties. Compared with strength measurement, obtaining elastic properties, however, needs much additional efforts in measurement of the 
elastic forces and deformations. Thus, few studies had concerned with these parameters systematically. The present study seeks to investigate the elastic mechanical properties of geopolymer-based materials, i.e., the Young's, bulk and shear moduli and Poisson's ratio, that are indispensable parameters to calculate the internal forces and deformations of the structures made with geopolymer, especially the ones worked under the spatial stress state, like building foundations, bridges and dams.

It has been shown that the Young's modulus of a geopolymer-based material (paste, mortar or concrete) strongly depends on the composition (nature of raw materials and mixture), synthesis process, curing time and temperature [4, 5, 30, 31]. Duxson et al. [4, 5] measured the Young's modulus of metakalin-based geopolymer (MKG) pastes with different $\mathrm{Si} / \mathrm{Al}$ ratios and alkali types. They found that the compositional factors have complex effects on the Young's moduli of the geopolymers and these effects are strongly correlated with the changes in microstructure of the geopolymer matrix. Further microindentation tests on Na and K-based MKG pastes by Lizcano et al. [30] also indicated the composition depended mechanical properties. Similar observations can be found for fly-ash-based geopolymer pastes [32]. Meanwhile, literature surveying indicated that the knowledge about Poisson's ratio of geopolymer-type materials is rather insufficient, given that Poison's ratio of the materials is significantly important for engineering application as it measures the ratio of deformations in different directions. Based on the values of Young's modulus and Poisson ratio, other elastic parameters, e.g., bulk modulus and shear modulus, can be obtained directly. It thus provides valuable scientific and engineering incentives to investigate the elastic properties of geoploymer-type materials and understand their composition correlations. In the present study, comprehensive experimental tests are conducted to measure the Young's, bulk and shear moduli and Poisson's ratio of MGK pastes. To understand their correlations with the composition, two series of MKG pastes are synthesized by controlling, respectively, dosage of the alkali equivalent to aluminosilicate material within a range of $10 \%-50 \%$ and molar ratio of $\mathrm{SiO}_{2}$ to $\mathrm{Na}_{2} \mathrm{O}$ in activator within a range of 1.25-2.25. With the information of stress-strain curves and microstructures, deepened discussion is performed to understand the fracture behaviors of the MKG pastes under compression tests and to elucidate how composition impacts the elastic properties. The results of the study may help to design and tailor MKG materials for further engineering applications. 
Table 1: Chemical composition of the metakaolin powder

\begin{tabular}{llllllllll}
\hline Component & $\mathrm{Al}_{2} \mathrm{O}_{3}$ & $\mathrm{SiO}_{2}$ & $\mathrm{~K}_{2} \mathrm{O}$ & $\mathrm{Na}_{2} \mathrm{O}$ & $\mathrm{CaO}$ & $\mathrm{TiO}_{2}$ & $\mathrm{Fe}_{2} \mathrm{O}_{3}$ & $\mathrm{LOI}$ \\
\hline Mass content (\%) & 39.68 & 57.26 & 0.21 & 0.27 & 0.04 & 1.78 & 0.43 & 0.34 \\
\hline
\end{tabular}

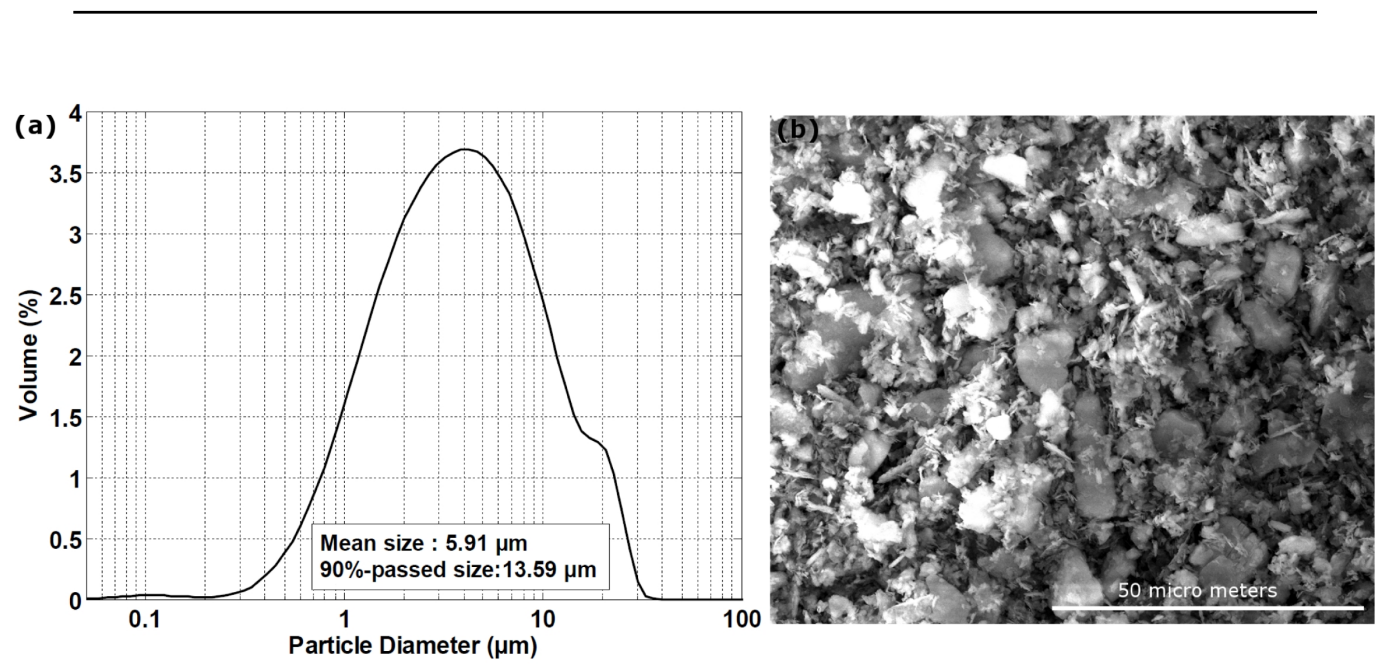

Figure 1: (a) Particle size distribution and (b) SEM photograph of the metakaolin powder.

\section{Experimental programme}

\subsection{Materials}

A commercial MK powder (Metamax, Basf Co.) was used as the aluminosilicate source of geopolymer. The chemical composition of the MK powder was analyzed by an X-Ray Fluorescence analysis (XRF-1800, Shimadzu). The aluminate and silicate occupy around $97 \%$ of the total mass; see Table 1 for the detailed composition data. The particle size distribution of the MK powder was measured by using a Laser Particle Size Analysis (LS-230, Coulter). The mean particle size was $5.91 \mu \mathrm{m}$ and the $90 \%$-passed particle size was $13.59 \mathrm{~m}$ (Figure 1 (a)). The results of the particle size distribution are in accordance with the SEM observation (Figure 1 (b)).

A liquid sodium silicate and a pellet sodium hydrate were used to make the alkaline activator. The modulus of the liquid sodium silicate, defined as the molar ratio of $\mathrm{SiO}_{2}$ to $\mathrm{Na}_{2} \mathrm{O}$ in the liquid sodium silicate, was 2.87. The pellet sodium hydrate was AR level and its purity was $96 \%$. The activator solutions were prepared by mixing proper amount of liquid sodium silicate, pellet sodium hydrate and water according to the required modulus of silicate. They were made, enclosed and stored at a room temperature of $20 \pm 1^{\circ} \mathrm{C}$ for at least 24 hours before synthesis of geopolymer. Special precaution operation was not taken to exclude $\mathrm{CO}_{2}$ in the solutions. 


\subsection{Mixture design}

As aforementioned, $\mathrm{Si} / \mathrm{Al}$ ratio and/or $\mathrm{M} / \mathrm{Si}$ ratio (or $\mathrm{M} / \mathrm{Al}$ ) can affect the polymeric character and the polymerization degree of a geopolymer, most experiments were designed by controlling $\mathrm{Si} / \mathrm{Al}$ ratio or $\mathrm{M} / \mathrm{Si}$ ratio or both [1, 3-5, 23]. However, this requires very careful measurement of the raw powders and activators as both the $\mathrm{Si} / \mathrm{Al}$ ratio and $\mathrm{M} / \mathrm{Si}$ ratio of the aimed geopolymer depend on chemical composition of the raw powders and activators, which may cause inconvenient engineering applications. Alternatively, a strategy for geopolymer mixture design can be just controlling mass (or molar) ratios of key ingredients, and the detailed Si/Al ratio and $\mathrm{M} / \mathrm{Si}$ (or M/Al) ratio can be calculated accordingly. This strategy has been used for mixture design of MKG foams [33, 34]. According to the strategy, the composition of a geopolymer can be controlled by three parameters, mass percentage of the alkali equivalent to the aluminosilicate material $(\mathrm{AE} \%)$, molar ratio of $\mathrm{SiO}_{2}$ to $\mathrm{Na}_{2} \mathrm{O}$ in activator (or modulus of silicate-Ms), and mass content of water in mixture $\left(\mathrm{H}_{2} \mathrm{O} \%\right)$, which can be expressed as follows,

$$
\begin{aligned}
\mathrm{AE} \% & =\frac{m\left(\mathrm{Na}_{2} \mathrm{O}\right)_{\text {Activator }}}{m\left(\mathrm{MK}_{\text {powder }}\right)} \times 100 \% \\
\mathrm{Ms} & =\frac{m o l\left(\mathrm{SiO}_{2}\right)_{\text {Activator }}}{m o l\left(\mathrm{Na}_{2} \mathrm{O}\right)_{\text {Activator }}} \\
\mathrm{H}_{2} \mathrm{O} \% & =\frac{m\left(\mathrm{H}_{2} \mathrm{O}\right)_{\text {Mixture }}}{m(\text { Mixture })} \times 100 \%
\end{aligned}
$$

where $\operatorname{mol}(\cdot)$ denotes the molar content and $\mathrm{m}(\cdot)$ denotes the mass content.

To investigate the possible composition influences on the elastic mechanical properties of MKG-based materials, two series of MKG pastes by controlling AE dosage and Ms level were designed. The first group of the MKG pastes required a constant $\mathrm{Ms}$ level of the activator, $\mathrm{Ms}=1.5$, and a variable of $\mathrm{AE}$ dosage changing from $10 \%$ to $50 \%$ by a stepwise increase of $10 \%$. In the second group of the MKG pastes, Ms changed from 1.25 to 2.25 by a stepwise increase of 0.25 with a constant AE dosage of $25 \%$. For the both groups of the MKG pastes, the total water content was controlled to be $41 \%$. The detail synthesis proportions of the MKG pastes are listed in Table 2 Note that in Table

2 the required mass of water are different for the mixtures because the activator contains different amount of water for each mixture. The detailed $\mathrm{Si} / \mathrm{Al}$ ratio and $\mathrm{Na} / \mathrm{Si}$ ratio for all the mixtures based on mass conservation are present in the last two columns of Table 2. The obtained MKG pastes have final $\mathrm{Si} / \mathrm{Al}$ and $\mathrm{Na} / \mathrm{Al}$ ratios similar 
Table 2: Synthesis mixture of the AE- and Ms-grouped MKG pastes

\begin{tabular}{llllllll}
\hline Composition & MK powder $(\mathrm{g})$ & Activator $(\mathrm{g})$ & Water $(\mathrm{g})$ & $\mathrm{Ms}(-)$ & $\mathrm{AE}(\%)$ & $\mathrm{Si} / \mathrm{Al}(-)$ & $\mathrm{Na} / \mathrm{Al}(-)$ \\
\hline AE-grouped & MKG pastes $(\mathrm{Ms}=1.5)$ & & & & & \\
AE10 & 677 & 389 & 378 & 1.5 & 10 & 1.5 & 0.4 \\
AE20 & 500 & 575 & 211 & 1.5 & 20 & 1.8 & 0.8 \\
AE30 & 430 & 741 & 123 & 1.5 & 30 & 2.2 & 1.3 \\
AE40 & 375 & 862 & 56 & 1.5 & 40 & 2.5 & 1.7 \\
AE50 & 330 & 948 & 5 & 1.5 & 50 & 2.8 & 2.1 \\
\hline Ms-grouped MKG pastes (AE=25\%) & 619 & 187 & 1.25 & 25 & 1.9 & 1.0 \\
Ms125 & 480 & 661 & 163 & 1.50 & 25 & 2.0 & 1.0 \\
Ms150 & 460 & 697 & 140 & 1.75 & 25 & 2.1 & 1.0 \\
Ms175 & 440 & 774 & 122 & 2.00 & 25 & 2.3 & 1.0 \\
Ms200 & 430 & 770 & 102 & 2.25 & 25 & 2.4 & 1.0 \\
Ms225 & 410 & & & & & & \\
\hline
\end{tabular}

with those prepared by Rowles and O'Connor [24], i.e. Si/Al ratios ranging between 1.08-3.0 and Na/Al ratios between $0.51-2.0$.

\subsection{Specimen preparation}

The fresh MKG pastes were made in a Hobart mixer. Firstly, the prepared activators, MK powders and additional distilled water were weighed according to Table 2. Then the activators were added into the mixing bowl. While the activators were being stirred, the MK powders and additional distilled water were gradually added in. After 3 to 5 minutes mixing, the mixture became smooth slurry (fresh paste). It was then poured into cylindrical moulds with diameter of $37 \mathrm{~mm}$ and length of $85 \mathrm{~mm}$. The casted moulds were then vibrated for 2 minutes to get rid of bubbles.

This is important for the high Ms level specimens, as the viscosity of the activator solution is high, leading to sticky pastes. Consequentially, the bad fluidity of the pastes may increase the heterogeneity of the MK geopolymer, which tends to lower the strength. After that, the cylindrical specimens, together with the moulds, were sealed up with plastic films and moved into a curing chamber with temperature controlled to be $20 \pm 1^{\circ} \mathrm{C}$ and relatively humidity above 


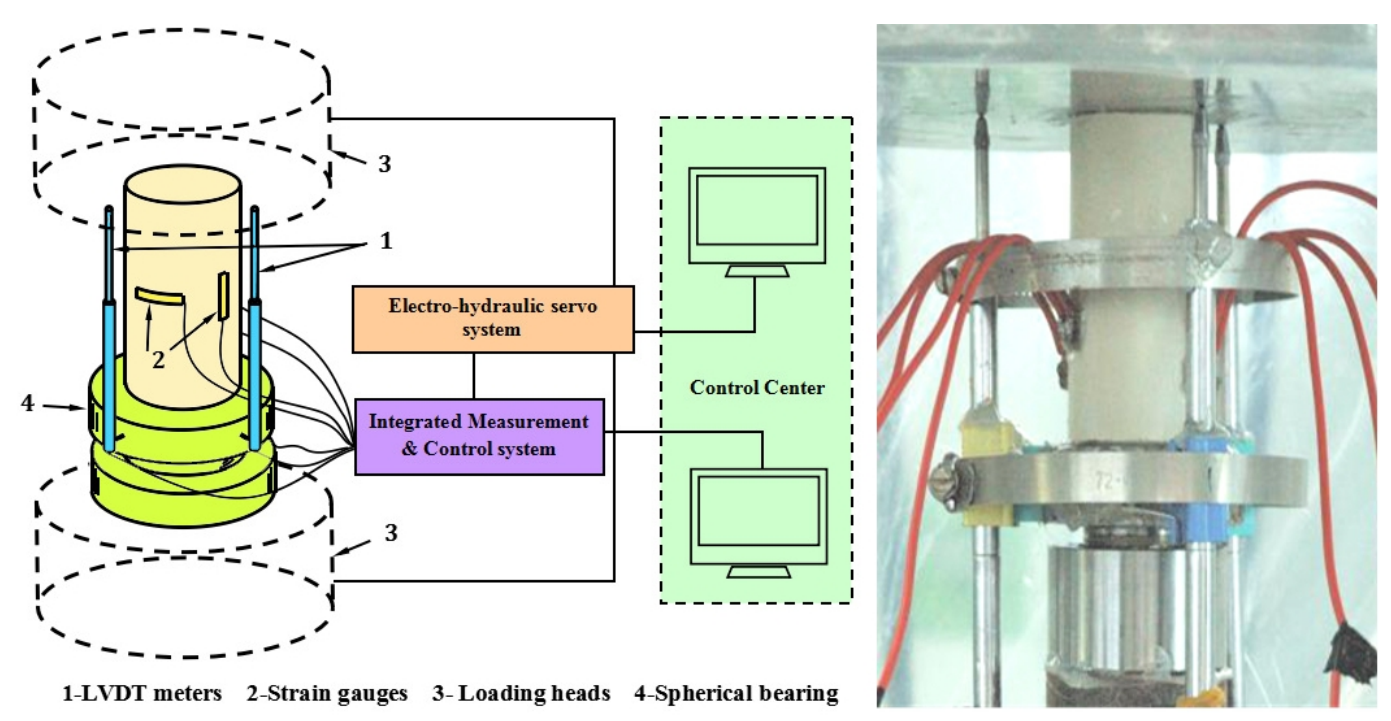

Figure 2: Schematic illustration of the measurement system (left) and an in-situ picture of a specimen and apparatus under testing (right).

90\%. After 7 days of curing, the specimens were demoulded and moved into sealed plastic bags to avoid the possible carbonation in the air during the hardening process. The specimens were continued curing in the same curing chamber for 21 days. Then the MKG paste specimens were prepared readily for elastic mechanical and microstructure tests.

\subsection{Mechanical measurement}

The compression test was operated with an Instron 8802 full-functional test machine. By aid of its electro-hydraulic servo system, the moving speed of the loading head was maintained at $0.48 \mathrm{~mm} / \mathrm{min}$. In order to keep uniaxial loading, a spherical bearing was installed between the specimen and lower loading head. The load was measured by a force sensor attached to the upper loading head. As the test went on, the forces were recorded, of which the maximum values were used to calculate the compressive strength.

Before the mechanical tests, all the MKG specimens were polished at the two ends to eliminate the possible stress concentration and friction between the surfaces of the specimens and loading heads. The height of the polished specimens was kept at $80 \pm 0.5 \mathrm{~mm}$ with an aspect length-to-diameter ratio of 2.16 . In order to achieve a statistical analysis, three specimens were tested for each mixture.

In order to measure the elastic deformation, four strain gauges were glued at the middle of each specimen. Two gauges were placed along the axial direction and the other two along the lateral direction. Beside the strain gauges, three LVDT meters were also erected between the upper loading head and the spherical bearing. The LVDTs were 
used to measure the total axial deformation of the MKG specimens and to track the deformation after failure of the strain gauges. Figure 2 shows the entire arrangement of the measurement system. The measured data were recorded simultaneously by an Integrated Measurement \& Control system, which provided stress-strain curves of the cylindrical MKG specimens.

According to Hooke's Law, stress and strain of a cylindrical elastic solid under a uniaxial compression have relationships displayed in Eqn. 2,

$$
\begin{aligned}
& \sigma_{z}=E \varepsilon_{z} \\
& \sigma_{z}=\frac{-E \varepsilon_{\theta}}{\nu}=\frac{-E \varepsilon_{r}}{\nu} \\
& \sigma_{r}=\sigma_{\theta}=\tau_{r z}=\tau_{\theta z}=\tau_{r \theta}=0 \\
& \gamma_{r z}=\gamma_{\theta z}=\gamma_{r \theta}=0
\end{aligned}
$$

where, $E$ and $\nu$ are the Young's modulus and Poisson's ratio of the solid, and the subscripts $z, r$ and $\theta$ represent the axes along the axial, radial and lateral directions of the cylinder respectively.

By fitting the Eqns. (2a) and (b) to the measured stress-axial strain curve and stress-lateral strain curve of the cylindrical solid under uniaxial compression in the elastic stage, the Young's modulus, $E$, and Poisson's ratio, $\nu$, of the solid could be derived. Once the Young's modulus and Poisson's ratio are determined, the bulk modulus, $K$, and the shear modulus, $G$, of the solid can be calculated by,

$$
K=\frac{E}{3(1-2 \nu)}
$$

and

$$
G=\frac{E}{2(1+\nu)}
$$

In this paper, the fitting process was performed by using the curve fitting toolbox in MATLAB software to determine the Young's modulus and Poisson's ratio of the MKG specimens, and the bulk and shear moduli were evaluated by Eqns. (3) and (4).

\subsection{ESEM-EDS analysis}

The microstructure of the MKG pastes was observed and analyzed using a FEI Quanta FEG650 field emission environmental scanning electronic microscopy (ESEM) with energy dispersive spectrometer (EDS). The samples for 
ESEM-EDS analysis were prepared from the crushed specimens after the compression test. In order to preserve the original topography of the fracture surfaces, all the samples were only cut into an appropriate size without polishing of the observation surfaces. An accelerating voltage of $20 \mathrm{kV}$ was selected, because a higher voltage may damage the microstructure of the samples, while a lower voltage may lead to grainy results. The working distance was $10.5 \mathrm{~mm}$ and the spot was controlled as 3.5 .

\section{Result and discussion}

\subsection{Compressive strength}

The compressive strengths of different mixtures are displayed in Figure 3 In general, the compressive strengths of the MKG pastes show a composition dependent behavior, and the average values are comparable with those of the OPC pastes with w/c ratio of 0.5 under normal curing conditions (20 $\mathrm{MPa}-40 \mathrm{MPa}$ [35]). It can be recognized from Figure 3 a) that AE dosage of the MKG pastes has a dual effect on the compressive strengths. When AE\% increases from $10 \%$ to $40 \%$, the compressive strengths are augmented from $4.2 \mathrm{MPa}$ to $36 \mathrm{MPa}$, increased by around $875 \%$. As AE\% further increases from $40 \%$ to $50 \%$, the compressive strengths are decreased sharply from $36 \mathrm{MPa}$ to $17 \mathrm{MPa}$, by approximately 56\%. The maximum value of the compressive strength appears for the $\mathrm{AE} 40$ specimens $(\mathrm{Si} / \mathrm{Al}=2.42$, Table 2). This dual effect of the alkali content on the mechanical strength of the MKG pastes is consistent with the research findings of the previous studies, e.g. Rowles and O'Connor [24] and Steveson and Sagoe-Crentsil [50], while some investigations reported that the compressive strengths of MKG pastes increase with the alkaline content or alkaline concentration increasing monotonously [28]. Note that curing conditions of $70{ }^{\circ} \mathrm{C}$ in first 24 hours for the specimens in Ref. [24] and $85{ }^{\circ} \mathrm{C}$ in first 2 hours for the specimens in Ref. [50] were performed. It indicates a proper level of alkali content in geopolymerization process [36]. Below that level, the alkaline reactant provided by the activator is insufficient to dissolve the powder materials and form the geopolymer matrix. But when the alkali content is beyond that level, the excess alkali would appear in the geopolymer matrix and weaken the structure formed.

Figure 3(b) displays the compressive strengths of the MS-grouped MKG pastes. As is seen, as MS increases from 1.25 to 2.25 , the compressive strengths of the MKG pastes are promoted from $28 \mathrm{MPa}$ to $42 \mathrm{MPa}$, by about $44 \%$. The molar ratio of $\mathrm{SiO}_{2}$ to $\mathrm{Na}_{2} \mathrm{O}$ in the activator, $\mathrm{Ms}$, in fact, governs the element ratio of $\mathrm{Si} / \mathrm{Na}$ or $\mathrm{Si} / \mathrm{Al}$ in the mixture as the AE dosage was controlled at $25 \%(\mathrm{Na} / \mathrm{Al} \approx 1)$. The strong correlation between the $\mathrm{Si} / \mathrm{Na}$ ratio or 

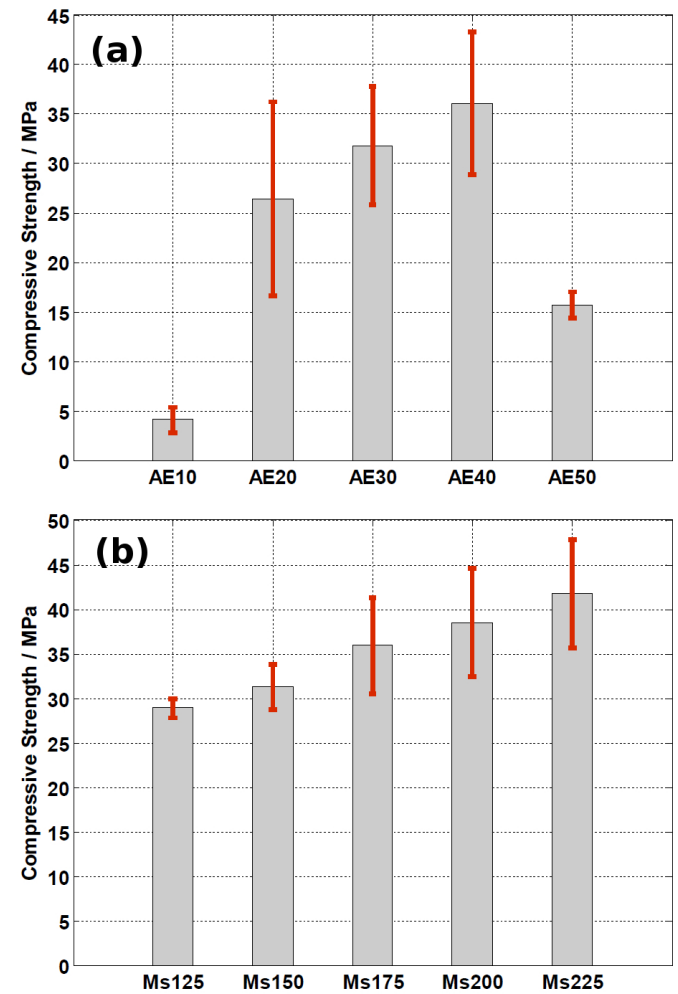

Figure 3: (a) Distribution of compressive strengths for the AE-grouped MKG pastes; (b) Distribution of compressive strengths for the Ms-grouped MKG pastes.

$\mathrm{Si} / \mathrm{Al}$ ratio (silicate content or Ms level in this study) and the mechanical strength could be found extensively, such as, Cheng et al.,[25, 26] Pelisser et al.[37] and Ozer and Soyer-Uzun[38]. In some studies (e.g., [5, 27, 39, 40]), a negative effect of a high Ms level on mechanical strength was also reported. The reasons for the weakening effect of the high Ms level on the compressive strength can be the poor workability of the geopolymer pastes due to the viscous nature of the sodium-silicate solution [27] and the inhibition effect of the high amount of the sodium-silicate solution on the geopolymerization process [41]. The observations of the negative effect of the Ms ratio of $2.25(\mathrm{Si} / \mathrm{Al} \approx 2.35)$ on the compressive strength of the MKG pastes, however, have not been shown in our experiment. It is reasonable because the $\mathrm{Si} / \mathrm{Al}$ ratio remains lower than $2.42(\mathrm{AE}=40 \%$ in Figure $3(\mathrm{a})$ ), at which the tested maximum compressive strength takes place. In addition, higher strengths have been reported for MKG materials with $\mathrm{Si} / \mathrm{Al}=2.5$ by Rowles and O'Connor [24] and Si/Al=2.75 by Zhang et al. [29]. 


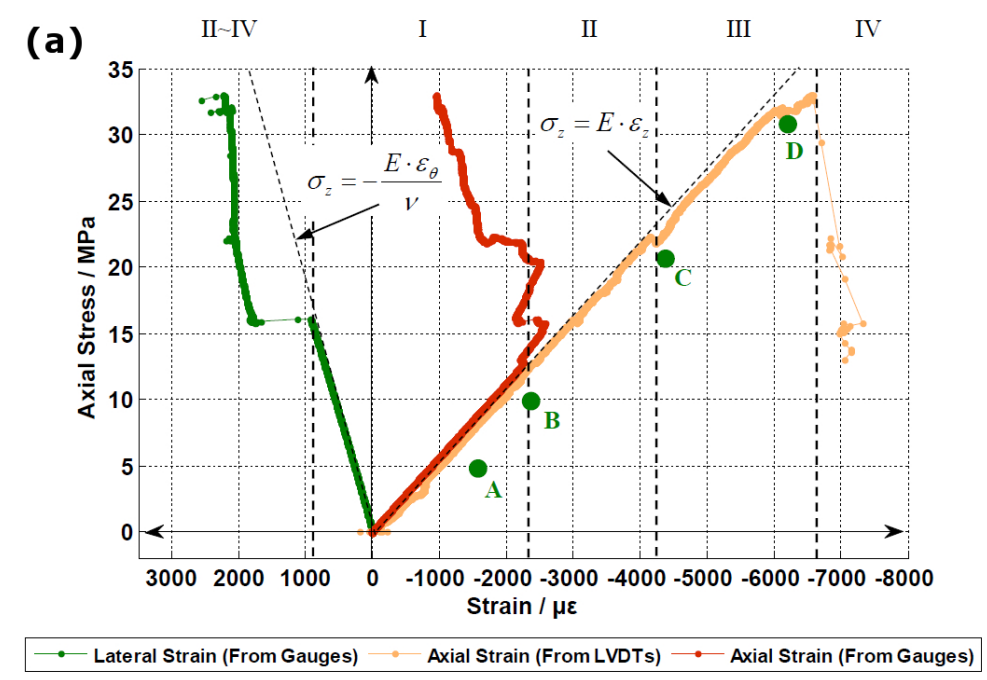

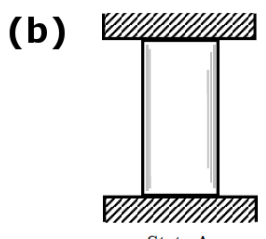

State A

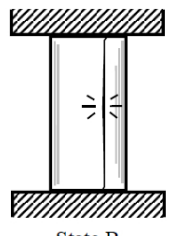

State B

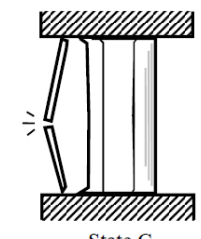

State C

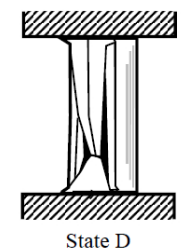

Figure 4: Typical mechanical behaviors of a MKG paste under uniaxial compression: (a) stress-strain curves and (b) configurations of the different fracture states

\subsection{Stress-strain behavior}

Stress-strain behavior of a solid is of importance to characterize the elastic properties and depict the fracture process of the material under loading. Among the total 30 axial load-strain and/or displacement tests of the MKG specimens, the test results of a Ms200 specimen were selected as an example to demonstrate the mechanical states and the corresponding superficial damages observed by the eyes; see Figure 4 The stress-strain curves of other mixtures are displayed in Figure 5. For clarity, only one sample for each composition is shown.

The results illustrated in Figures 4 and 5 may help to analyze the failure process of the MKG pastes under the uniaxial compression. According to our experiments, the failure process of the MKG pastes could be characterized by the following four stages.

\section{(1) Stage I: elastic stage}

During this stage, no visible damage could be recognized from the surfaces of the specimens, e.g., the State A illustrated in Figure $4(\mathrm{~b})$. The stress-strain curves measured by both the axial and lateral strain gauges are straight lines from the origin point. This indicates that the MKG specimens are under the linear elastic state. The characteristic 

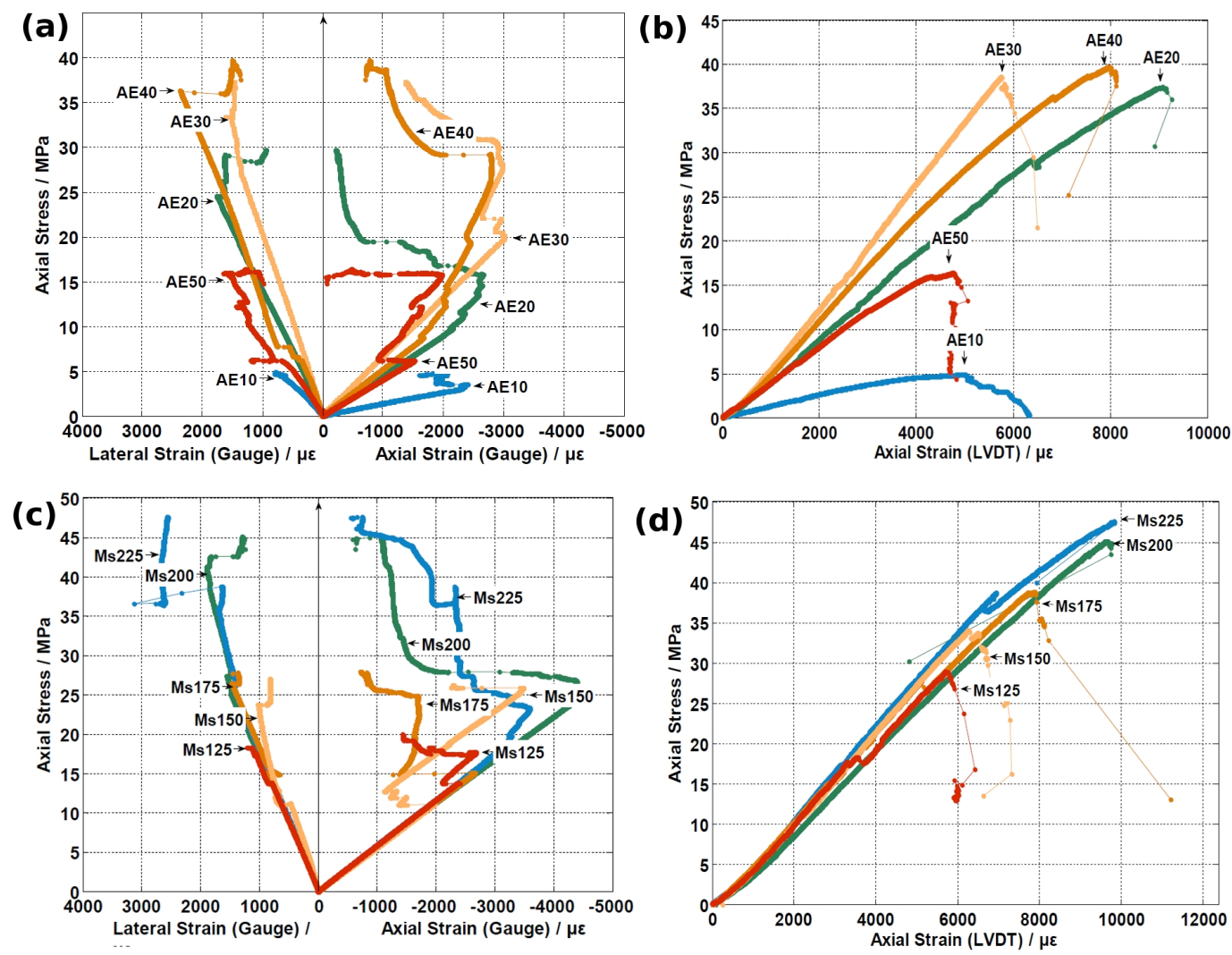

Figure 5: Stress-strain curves of the AE-grouped MKG specimens by (a) gauges and (b) LVDTs, and the Ms-grouped MKG specimens by (c) gauges and (d) LVDTs.

elastic properties, i.e., Young's, bulk and shear moduli and Poison's ratio, can be evaluated from the data in this stage. It is noteworthy that beginning parts of the stress-strain curves measured by the LVDTs show slight vibrations. The occurrences of the vibrations are found in a range of $0.5 \mathrm{MPa}$ to $6 \mathrm{MPa}$, usually $10 \%-20 \%$ of the ultimate strengths of the MKG specimens. Meanwhile the rests of the stress-strain curves remain strictly linear until the stresses reach about $60 \%-100 \%$ of the ultimate strengths. The slight vibrating behavior at the very beginning part of the stress-strain curves measured by the LVDTs could be attributed to the imperfect contact between the specimens and the loading heads, creating perturbation to the measured data. As the compression loads increase, this influence would be weakened and the stress-strain curves measured by the LVDTs would return to the linear behaviors and be consistent with the results measured by the gauges. The differences of the elastic moduli of all the MKG specimens between from the gauge data and the LVDT data are less than 5\%, suggesting the reliability of the measurement.

\section{(2)Stage II: crack initiation and propagation}


During this stage, some visible cracks along the axial direction emerge on the side surfaces of the specimens, e.g., the State B illustrated in Figure 4 b), and the crack density increases with increasing the compression loadings. It is difficult to identify the fracture extents of the MKG specimens under uniaxial loadings by the visible superficial cracks. The development of the axial and lateral strains with the compression loadings measured by the gauges, however, ma help to configure the fracture behaviors of the materials with obvious and direct transition points in the curves. For instance, when the axial stain arrives at around $-2200 \mu$, it turns from a linear plot against the stress to a non-linear form with further loading; and when the axial stress is promoted to around $16 \mathrm{MPa}$, the lateral strain is suddenly shifted from $900 \mu$ to $1800 \mu$; see Figure 4 a). The sudden-and-significant-strain shifts maybe due to the fact that the macro cracks propagate and penetrate through the areas in contact with the lateral gauges. The results suggest that crack initiation and propagation in the solid matrix have damaged the material to some extents, which biases the axial and lateral stress-strain curves. It is expected that the stresses corresponding to the shift points of the axial and lateral strains should be consistent. Unfortunately, our results present very scattered data of the shift points between the axial and lateral strains without statistic significance. The axial stress-strain curves by the LVDTs, however, remain keeping straight lines, because the cracks are local distributed, leaving the undamaged matrix to sustain further loadings.

\section{(3) Stage III: crack propagation}

In the stage, the cracks penetrate trough the matrix of the material, and superficial spalling appears with moderate and/or advanced splitting fracture damages; see the diagram State $\mathrm{C}$ in Figure $4 \mathrm{~b}$ ). The (absolute) values of the axial strain by the gauges tend to decrease, suggesting that the superficial part of the material that would shrink under compression initially has been fractured and might have been separated from the main matrix of the material. Meanwhile the lateral strain shows minor increases with increasing the compression loading, telling again the significant fracture damages in the material so that the local strain by the gauges could not represent the overall mechanical behavior of the material. At the same time, the stress-strain curves measured by the LVDTs start to deviate from the linear trend with abrupt drops due to the fracture behaviors of the material. Due to the crack penetration through the material, its mechanical behavior becomes unstable. Several random shifts in both the axial and lateral strains would take place before the breakdown of the MKG specimens. These shifts divide the stress-strain curve into discrete parts; see Figure 5

(4) Stage IV: failure completing 
In this stage, the specimens can be broken into several parts as the splitting cracks are connected by shear failures inside the materials; see the State D illustrated in Figure $4(\mathrm{~b})$. Then the failure process enters the post-peak stage. In this stage, the superficial MKG materials that were adhered with the local axial and lateral gauges spalled out from the matrix, so the data of the gauges were useless. As the specimens are failed completely, the loads would have a sudden release as depicted by the axial stress-stain curves by the LVDTs shown in Figures 4, 5(b) and5(d). This sudden stress drop after peak load for geopolymer-based materials has been reported elsewhere [42-44]].

\subsection{Elastic properties}

The stress-strain curves measured by the strain gauges and LVDTs at Stage I could reveal the linear elastic behaviors of the MKG pastes. However, given that small perturbations of the linear stress-strain curves by the LVDTs take place at the very beginning loading periods, only the strains by the gauges at Stage I are adopted to calculate the Young's, bulk, shear moduli and Poisson's ratio of both the AE-grouped and Ms-grouped MKG pastes.

\subsubsection{Effect of AE dosage}

The calculated elastic properties of the AE-grouped MKG pastes are displayed in Figure 6 In general, the Young's moduli of the AE-grouped MKG pastes vary from 1.1 GPa to $6.1 \mathrm{GPa}$ that are systematically lower than those of typical OPC pastes (e.g. $10 \mathrm{GPa}$ to $40 \mathrm{GPa}$ depending on water to cement ratios, curing conditions and curing ages [45-47]), while the compressive strengths are in the range of $4 \mathrm{MPa}$ to $36 \mathrm{MPa}$ (Figure 3(a)) that are comparable with those of typical OPC pastes as discussed above. The observation of high strength and relatively low Young's modulus can be a notable mechanical feature of MKG type material. Similar to the dual effect of the AE dosage on the compressive strength of the MKG specimens, the plots of Young and shear moduli against AE dosage also show a ' $\Lambda$ ' like curve with the maximum Young and shear moduli for the AE30 specimens; see Figure 6a) and (d). As the AE dosage increases from 10\% to 30\%, the Young's and shear moduli of the MKG specimens increase respectively from 1.3 GPa to $6.1 \mathrm{GPa}$ and $0.55 \mathrm{GPa}$ to $2.4 \mathrm{GPa}$, and respectively by about $490 \%$ and $450 \%$. Further promotion of the AE dosage tends to decrease the Young and shear moduli. As shown in Figure 6(a) and (d), when the AE dosage increases from $30 \%$ to $50 \%$, the Young and shear moduli of the MKG specimens decrease respectively from $6.1 \mathrm{GPa}$ to $4.2 \mathrm{GPa}$ and from $2.4 \mathrm{GPa}$ to $1.5 \mathrm{GPa}$, and respectively by about $33 \%$ and $38 \%$.

Interestingly, simple and monotonous increases of the Poisson's ratio and bulk modulus of the MKG specimens 

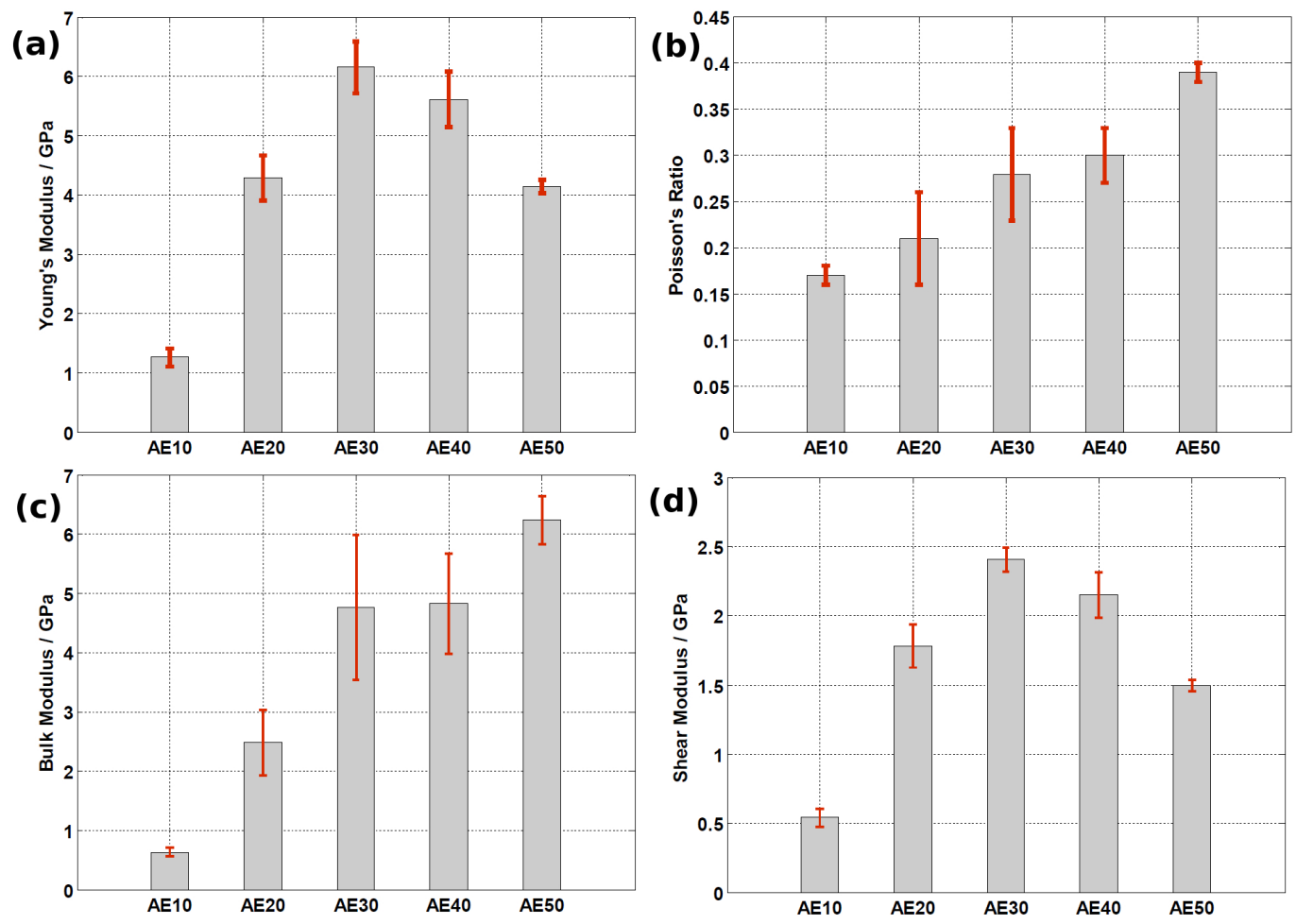

Figure 6: Elastic properties of the AE-grouped MKG specimens: (a) Young's modulus, (b) Poisson's ratio, (c) Bulk modulus and (d) shear modulus.

with the AE dosage increasing are observed in Figure 6(b) and (c). As the AE dosage is augmented from 10\% to 50\%, the Poisson's ratio and bulk modulus are increased respectively from 0.17 to 0.38 (by about 230\%) and $0.6 \mathrm{GPa}$ to 6.3 GPa (by about 980\%). The data of the Posson's ratio of the MKG pastes are much wider than the measured values in the literature (e.g. 0.2 to 0.27 for a fly-ash-based geopolymer under different curing temperatures reported by Nasvi et al. [48]), but are comparable with those of OPC pastes under different maturities or hydration degrees (e.g. from 0.15 with advanced maturity to around 0.5 with very low maturity for an OPC paste simulated by a finite element computation technique [45]). The bulk and shear moduli of the MKG specimens, however, are dramatically lower than those of OPC pastes (e.g. Young's modulus of $22 \mathrm{GPa}$ and bulk modulus of $14 \mathrm{GPa}$ for an OPC paste with w/c $=0.5$ [49]). The results suggest that the MKG pastes are a type of 'soft' material.

Using ESEM-EDS technique, the microscopic correlations between the elastic properties and the composition of the MKG specimens can be further analyzed. Figure 7 shows the micro scaled morphology of the fractured surfaces of the AE10, AE30 and AE50 samples in the ESEM photographs. For the AE10 sample, discrete and prism-shaped particles could be easily found out everywhere and the matrix is loosely constituted by these particles. The geopolymer 


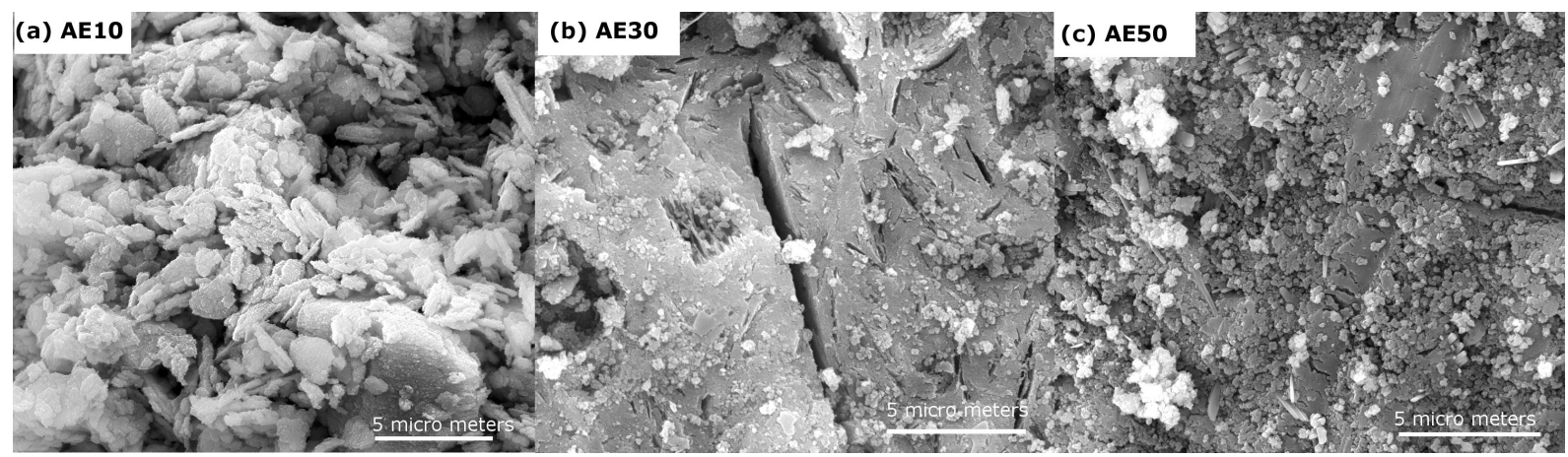

Figure 7: ESEM microstructures of (a) AE10, (b )AE30 and (c) AE50 MKG pastes.

gel can be hardly detected as most of the gel formed only on the surfaces of these particles. The binding effect of the geopolymer gel is thus relatively weak, supporting the previous observations that both the compressive strength and elastic modulus are very low. Recent study by He et al. [43] also reported a MKG paste with Si/Al ratio of 1.75 that consists of the similar patches of porous, discrete and prism-shaped particles and dense and continuous gel-like matrix. As the AE content is increased, e.g., to 30\%, the particles are wrapped or embedded in the geopolymer gel and the gel becomes the dominant phase of the matrix. The microstructure of the MKG paste is significantly densitified, yielding a tough and stiff matrix that sustains high compression loading and elastic deformation. This microstructure change agrees with the previous finding by Steveson and Sagoe-Crentsil [50]. Carefully examination of Figure 7 also indicates micro cracks around the particles and in the continuous matrix. The micro cracks, as suggested in [43], maybe induced by the compressive loading and shrinkage during geopolymerization process.

Chemically speaking, the alkali content of the activator solution would become a restriction of the reaction for the low-AE-dosage cases, because, in the process of geopolymerization reaction, alkali cations are incorporated into the (N)-A-S-H gel structure, e.g., to balance the net negative charge generated when $\mathrm{Al}^{3+}$ replaces $\mathrm{Si}^{4+}$ in the tetrahedral chain sites [1]. Obviously, when the AE dosage is relatively low, increasing the AE dosage tends to promote the extent of the geopolymerization reaction and produce more geopolymer gels that would be bound together to form the material matrix. Generally, the gel product has two effects on the matrix. The first one is the bonding effect that transforms the loosely packed particles into a hard framework, and the second one is the filling effect that eliminates the pore spaces and changes the porous solid into a compacted material. The former effect enhances the strength and stiffness of the matrix and the later effect increases the incompressibility of the matrix. As a result of the above mentioned mechanisms, the Young's modulus, Poisson's ratio, bulk modulus, shear modulus and compressive strength of the 
MKG pastes are all increased as the AE dosage is increased.

Theoretically, the amount of the AE consumption for the geopolymerization reaction has a upper limit for a mixture. So, much more introduction of the alkali would hardly promote the extent of the geopolymerization reaction. Instead, the excess alkali and silicate would be cumulated in the matrix, that are possible to weaken the bond strength and the homogeneity of the solid matrix. This can be evidenced by the ESEM observation of the AE40 MKG specimen as displayed in Figure 7(c). As is seen, the microstructure of the AE40 sample is much looser than that of the AE30 sample (e.g. Figures 7 b) and 8 (a)). Furthermore, some crystal-like or particle-like solids with a high $\mathrm{Na} / \mathrm{Si}$ ratio and/or Na/Al ratio can be observed for the AE40 sample as displayed in Figure 8(b) with the help of the ESEM-EDS analysis. It has been reported in previous studies that a high sodium content usually results in a weakened material structure because the low silica gels tend to form into discrete particulate units with poor polymerization rather than generating a continuous gel network [1, 24, 39, 43]. The findings in our experiments seem to confirm this trend. So it shows lower Young's and shear moduli and compressive strength of the AE40 pastes than those of the AE30 pastes. But due to the filling effect of the hydrated aluminate-silicate gel and these inclusions, the incompressibility of the matrix is still enhanced. It is thus reasonable that both the Poisson's ratio and bulk modulus of the MKG pastes continuously and monotonously increase with the AE dosage increasing.

\subsubsection{Effect of Ms level}

The calculated elastic properties of the Ms-grouped MKG pastes are shown in Figure 9. Obviously and interestingly, the Ms level has a weak impaction on the elastic properties of the MKG specimens. Specifically, the values of Young's modulus lay in the range of $5.5 \mathrm{GPa}-5.8 \mathrm{GPa}$, Poisson ratio of $0.27-0.33$, bulk modulus of $4.6 \mathrm{GPa}-5.3 \mathrm{GPa}$, and shear modulus of 2.1 GPa-2.3 GPa. The near constant values of the elastic properties of the Ms-grouped MKG specimens depicted in Figure 9 are somehow different with those of the values of compressive strength demonstrated in Figure 3(b). Again the results suggest a "soft but tough" mechanical feature of the MKG materials prepared in this study.

Towards a more reasonable evaluation, the statistical significance of the elastic parameters versus Ms level is analyzed using a variance analysis method [51]. The $\mathrm{F}$ test statistic of each parameter can be calculated by Eqn. 5 ,

$$
F=\frac{M S_{\text {level }}}{M S_{\text {error }}}=\frac{S S_{\text {level }} /\left(N_{\text {level }}-1\right)}{S S_{\text {error }} /\left(N_{\text {sample }}-1\right)}
$$




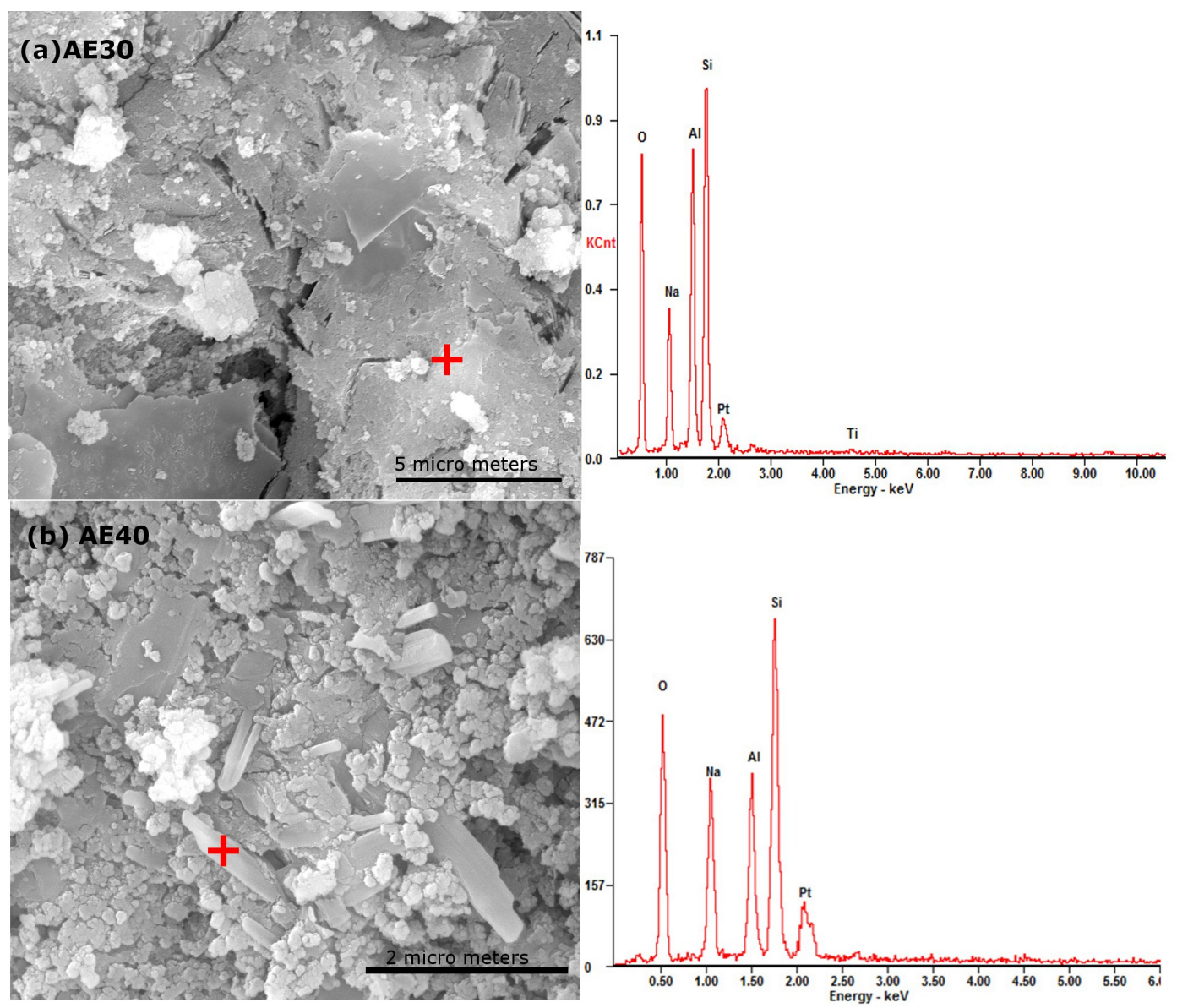

Figure 8: SEM-EDS results of (a) AE30 and (b) AE40 MKG pastes. 

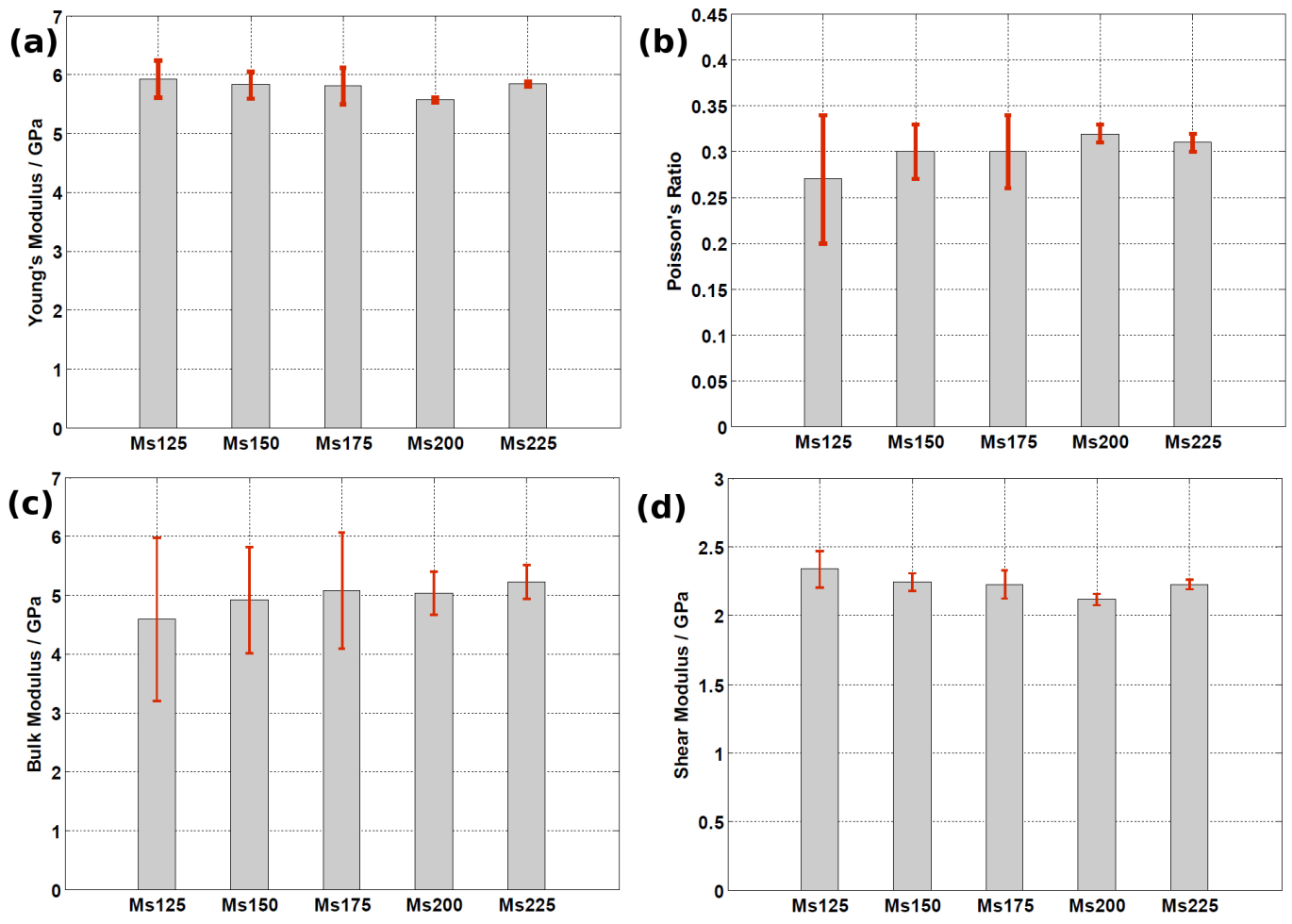

Figure 9: Elastic parameters of the Ms-grouped MKG specimens: (a)Young's modulus, (b) Poisson's ratio, (c) Bulk modulus and (d) shear modulus.

where, $M S_{\text {level }}$ and $S S_{\text {level }}$ are the mean square of deviations and the sum of squares of deviations between disparate levels of Ms; $M S_{\text {error }}$ and $S S_{\text {error }}$ are the mean square of deviations and the sum of squares of deviations within these levels; $N_{\text {level }}$ is the number of levels of Ms; $N_{\text {sample }}$ is the total number of samples in the Ms group. The significance of a relationship can be judged by a comparison between the critical $\mathrm{F}$ value acquired from the F-distribution and the analysis results. In the present study all the critical $\mathrm{F}$ values are acquired from the F-distribution with degree of freedom equals to ( $\left.N_{\text {level }}-1, N_{\text {sample }}-1\right)$ and the significance level equals to 0.05 .

Table 3: The results of analysis of variance for the Ms-grouped MKG specimens

\begin{tabular}{lccccccc}
\hline Property & $N_{\text {level }}$ & $N_{\text {sample }}$ & $M S_{\text {level }}$ & $M S_{\text {error }}$ & calculated F & Critical F & Significance \\
\hline Young's modulus & 5 & 15 & 0.0186 & 0.0502 & 0.3710 & 3.4780 & Insignificance \\
Poisson's ratio & 5 & 15 & 0.0003 & 0.0017 & 0.2009 & 3.4780 & Insignificance \\
Bulk modulus & 5 & 15 & 0.0575 & 0.7836 & 0.0733 & 3.4780 & Insignificance \\
Shear modulus & 5 & 15 & 0.0062 & 0.0069 & 0.9067 & 3.4780 & Insignificance \\
\hline
\end{tabular}


In Table 3 are summarized the variance analysis results of the elastic parameters of the Ms-grouped MKG specimens. In conclusion, the influences of the Ms level on all the elastic properties are insignificant in the tested range (1.25-2.25). The results found in this paper conform to a conclusion from the analysis by an extrapolation in Refs. [4, 5] that the Young's modulus may be said to be essentially constant within experimental uncertainty as $\mathrm{Si} / \mathrm{Al} \geq 1.65$ (corresponding to $\mathrm{Ms} \geq 1.0$ in this study). However, when the Ms level is beyond the test range, the influences of the Ms level on the elastic parameters may become to be significant [5, 30]. Therefore, further extensive experimental and theoretical (or modelling) investigations on the relevant issues are required in the future.

Although the Ms level may have a negligible influence on the elastic properties of the MKG pastes within the experiment range, it still remains unauthentic to state the same correlation of the Ms level to the microstructure of the geopolymer materials. On the contrary, our results reveal obvious microstructure changes as the Ms level changes based on the ESEM results; see Figure 10 for the exemplified SEM pictures of the Ms125, Ms175 and Ms225 specimens. Note that the microstructure information (e.g. specific surface area, mean pore radius, nanoscaled elastic properties) for all the Ms-grouped samples were not provided in detail, because the selected ESEM pictures seem tough to depict the microstructure changes by the variations of the Ms level. As seen in Figure 10, apparently, all the samples show relatively tight compacted microstructure with some obvious cracks appearing in the material matrix, because the SEM samples were prepared from the fractured specimens and the texture may shrink heterogeneously during geopolymerization as discussed above. Because of the relatively dense microstructure, all the Ms-grouped specimens display constants of the elastic parameters; see Figure 9 However, close examination on the ESEM pictures displayed in Figure 10, together with the EDS results of the Ms225 paste, implies that a poly-aluminate-silicate phase (or a macro aluminate-silicate "crystal" phase) can be found in the geopolymer gels, and the size and the amount of this phase increase with the Ms level increasing. The interactions between the macro crystals and the geopolymer gels seem to be strong enough to sustain large compressive loading as there are no obvious cracks appear along the interfaces between them. Consequentially, the macro "crystals" may suppress the nucleation and/or obstruct the propagation of the cracks under loading. In other words, the poly-aluminate-silicate solids, acting as aggregates, may improve the material strength under compression test as shown in Figure 3 (b). 

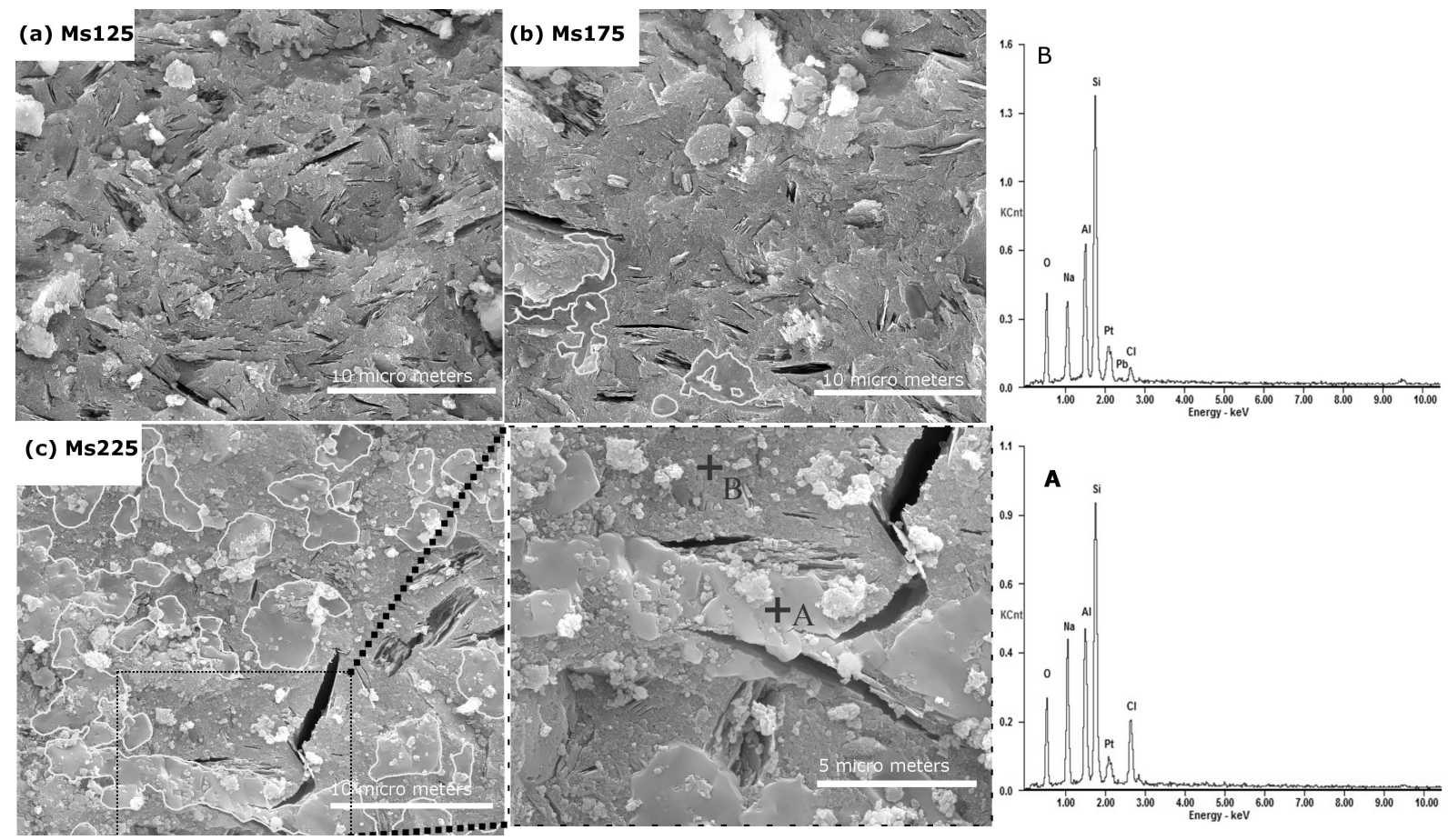

Figure 10: SEM-EDS results of the selected Ms-grouped MKG pastes: (a) Ms125, (b)Ms175 and (c) Ms225.

\subsection{Quantitative assessment}

General qualitative evaluations of the compositional factors that affect mechanical properties of geopolymer-type materials help to understand the mechanisms of the strength development during composition-associated geopolymerization. However, it is inadequate to achieve excellent designs and engineering uses of the materials. To this end, a quantitative assessment of the correlations between the elastic properties and the composition of a MKG material is thus of great necessity. Due to the fact that the influences of the Ms level on the elastic properties of the MKG specimens are statistically insignificant, and the bulk and shear moduli can be derived from the Young's modulus and Poisson ratio, this contribution hereby analyzes and discusses the data of the Young's modulus and Poisson's ratio determined from the AE-grouped MKG pastes.

As previous mentioned, the AE dosage has the dual effect on the Young's modulus of the MKG pastes. This relationship could be formulated by a quadratic double-logarithmic (QDL) function as presented in Eqn. (6),

$$
E=E^{*} K_{\mathrm{AE} \%}=E^{*} \exp \left(-\kappa \ln ^{2}(\chi)\right), \quad \chi=\frac{\mathrm{AE} \%}{\mathrm{AE} \%^{*}}, \quad \kappa>0
$$

In the QDL function, the Young's modulus is expressed as the product of the specific Young's modulus ( $\left.E^{*}\right)$ and the influential coefficient of the AE dosage $\left(K_{\mathrm{AE} \%}\right)$. The logarithm of $K_{\mathrm{AE} \%}$ has a quadratic relationship with the 


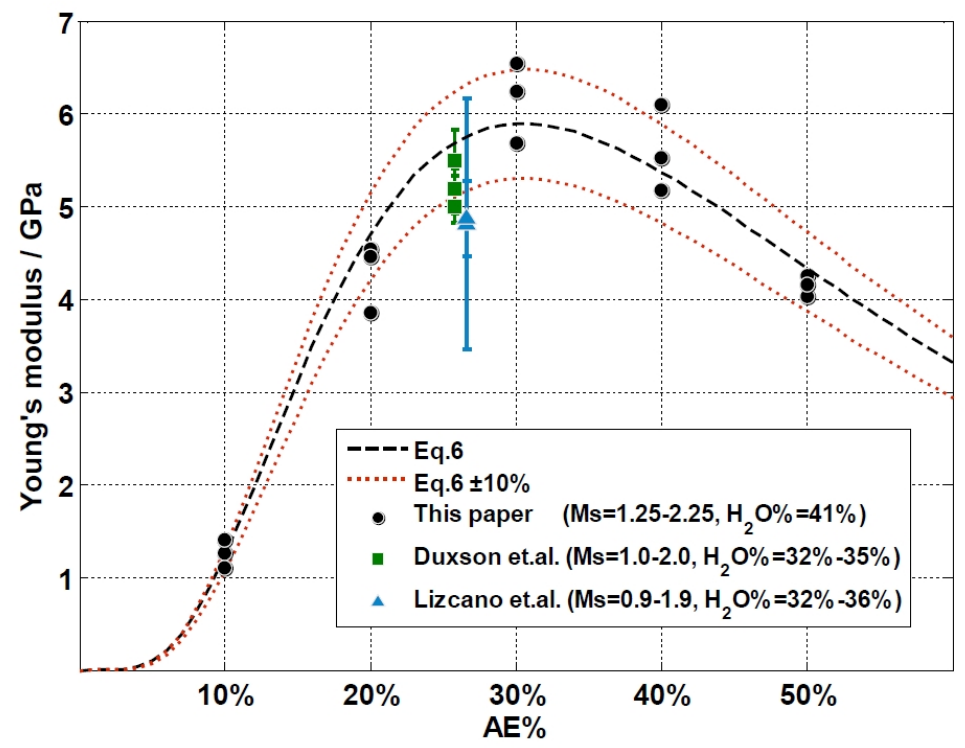

Figure 11: Quantitative correlations between the Young's modulus and the AE dosage of the MKG pastes by the estimation formulation of Eq. (6). For comparison purpose, the experimental data in [4] 5] 30] are adopted.

logarithm of the nondimensionalized factor $\chi$ that represents the relative ratio of the $\mathrm{AE}$ dosage to the specific $\mathrm{AE}$ dosage $\left(\mathrm{AE} \%^{*}\right)$. When $\mathrm{AE} \%$ equals to $\mathrm{AE} \% *(\chi=1)$, the Young's modulus of the MKG material would be identical to its specific value $\left(E=E^{*}\right)$. When $\mathrm{AE} \%$ deviates from $\mathrm{AE} \%$, i.e., $\chi$ approaches zero or infinity, the Young's modulus of the MKG material would have a trend towards zero. Moreover, the shape factor $\kappa$ is positive and provides a reference index to describe the sensitivity of the Young's modulus to the variation of the AE content. If $\kappa$ is big, it indicates that the Young's modulus would rapidly decrease when AE\% deviates from AE\%*. If $\kappa$ is small, the Young's modulus would have a mild tolerance to the deviation of $\mathrm{AE} \%$ from $\mathrm{AE} \%$ *

Figure 11 shows the measured Young moduli versus the AE dosages and the fitting curve. As is seen, Eq.(6) can well model the dual effect of the AE dosage on the Young's moduli of the MKG pastes. Most of the experimental results fall within the prediction bound of the estimation function with $10 \%$ uncertainty. The estimated $E^{*}, \mathrm{AE}^{*}$ and $\kappa$ of the AE-grouped MKG pastes are $5.89 \mathrm{GPa}, 30.52 \%$ and 1.29 respectively. The correlation coefficient of this formulation is 0.95 .

For comparison, some experimental results in the literature are selected. For example, in the previous studies by Duxson et al. [4, 5], the Young's moduli of the MKG pastes with $\mathrm{Ms}=1.0-2.0, \mathrm{Na}_{2} \mathrm{O} / \mathrm{Al}_{2} \mathrm{O}_{3}=1(\mathrm{AE} \% \approx 25 \%)$ and $\mathrm{H}_{2} \mathrm{O} / \mathrm{Na}_{2} \mathrm{O} \approx 11\left(\mathrm{H}_{2} \mathrm{O} \%=32 \%-35 \%\right.$ with the average value of $33 \%$ based on the mixtures and compositions given 
in [4, 5]), were about 4.8 GPa-5.9 GPa. In a similar study by Lizcano et al.[30], the Young's modulus of Na-based MKG pastes with $\mathrm{SiO}_{2} / \mathrm{Al}_{2} \mathrm{O}_{3}=1.5-2(\mathrm{Ms}=0.9-1.9), \mathrm{Na}_{2} \mathrm{O} / \mathrm{Al}_{2} \mathrm{O}_{3}=1(\mathrm{AE} \% \approx 26 \%$ based on the mixtures and compositions given in [30] $), \mathrm{H}_{2} \mathrm{O} / \mathrm{Na}_{2} \mathrm{O}=11\left(\mathrm{H}_{2} \mathrm{O} \%=32 \%-36 \%\right.$ with the average value of $\left.34 \%\right)$ were about 3.4 GPa-6.1 GPa. The experimental results in [4, 5, 30] show an acceptable consistency to the estimation by Eqn. (6), as the different experimental schemes (such as, raw materials, curing conditions and test constraints) were used. It has been recognized that raising the curing temperature tends to enlarge the pore size and increase the pore volume of geopolymer-type porous material [52]. The pore structure changes, in turn, alter the mechanical properties of the material. For example, in the study by Lizcano et al. [30], some MKG specimens were cured at $80{ }^{\circ} \mathrm{C}$, which may weaken the connections of the formed geopolymers. It is thus reasonably that the Young's moduli of the MKG pastes in [30] are below the estimations in the study. The investigations on the effect of temperature on the mechanical behaviors of MKG materials are extensive, e.g. Mo et al. [53]. Moreover, the short curing age (2-3 days) in Lizcano's experiment may also lower the Young's moduli of the MKG pastes.

Experiment tests indicate that the values of Poisson's ratio of the MKG pastes increase progressively as the AE dosage increases from $10 \%$ to $50 \%$. However, most solids are volumetric compressible, suggesting that the bulk modulus of the material cannot be infinite. So the Poisson's ratio of a real elastic solid has a theoretical limit of 0.5 . This tells that simple increasing functions, such as the linear function or exponential function, are not recommended to represent the relationship between the Young's modulus and AE dosage determined in this study. A sigmoid function expressed by Eqn. 7 is proposed in this study to capture the relationship,

$$
\nu=\left(\nu_{0}-0.5\right) \exp \left(-\lambda \mathrm{AE} \%^{2}\right)+0.5, \quad \lambda>0
$$

In this function, the Poisson's ratio, $\nu$, has two limits: the initial value $\nu_{0}$ as $\mathrm{AE} \%=0$ and the theoretical limit $(\nu=0.5)$ as $\mathrm{AE} \%$ approaches infinity. Between these two limits, the formulation is a smooth sigmoid curve. $\lambda$ is a shape factor that controls the increasing rate of the Poisson's ratio versus the AE dosage.

Figure 12 displays the experimental data of the Poisson's ratios of the MKG pasts with different AE dosages and the correlation curves fitted by Eq. (7). Clearly, the proposed sigmoid function can fit the experimental data well with the correlation coefficient of 0.87 . it shows that $\nu_{0}=0.16$ and $\lambda=4.17$, indicating that the Poisson's ratio of the pure MK solid is 0.16 , and that of the neat sodium silicate solution is 0.5 . The remarkable changes of the Young modulus and Poisson ratio with the AE dosage attract further attentions on uses of geopolymers in practice, and the relevant 


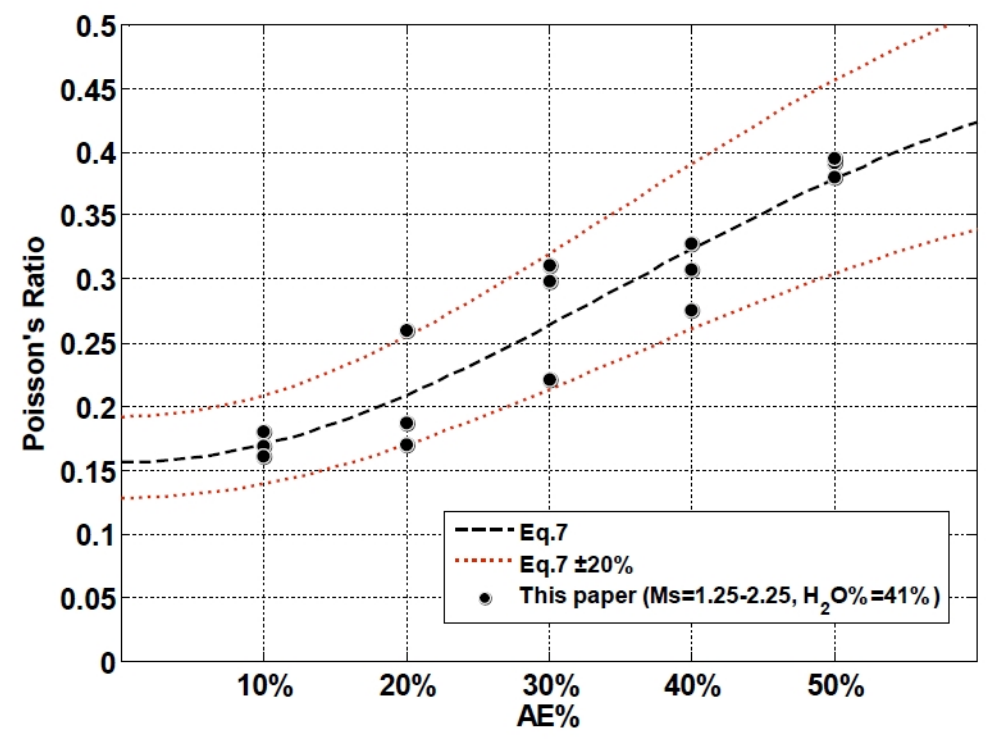

Figure 12: Quantitative correlations between the Poisson's ratio and the AE dosage of the MKG pastes by the estimation formulation of Eqn. 7

\section{issues therefore deserve rigorous investigation in the future.}

\section{Conclusions}

In the present study, AE-grouped and Ms-grouped MKG pastes were synthesized, the axial and lateral stressstrain curves were measured and the microstructures were characterized. Furthermore, this investigation seeks to determine the elastic properties of the MKG pastes, i.e., the Young's, bulk and shear moduli and the Poisson's ratio, and correlate the data with the composition and microstructure. The obtained results yield the conclusions as follow:

1, The AE dosage has a dual effect on the compressive strength with a best dosage of $40 \%$, whereas the Ms level displays a monotonous promoting effect to the compressive strength.

2, The fracture behavior of the MKG pastes can be characterized by a four-stage failure process: (a) the stage of elastic deformation without cracks; (b) the stage of slight fracture deformation with visible superficial cracks by crack initiation and propagation; (c) the stage of moderate fracture damage with superficial spalling of the material by crack penetration and percolation; and (d) the stage of fracture failure.

3 , The plots of Young and shear moduli of the MGK pastes to the AE dosage also show a ' $\Lambda$ ' like curve with the maximum values at AE30. This relationship can be characterized by a quadratic double-logarithmic function.

4, It shows simple and monotonous increases of the Poisson's ratio and bulk modulus of the MKG pastes with the 
AE dosage increasing, which can be characterized by a sigmoid function.

5, It shows constant values of Young's, bulk and shear moduli and Poisson's ratio of the Ms-grouped MKG without statistic significance according to a variance analysis method.

6. The MKG paste is a 'soft but tough' material that shows relative low elastic modulus and high compressive strength. A densified and well polymerized network of geopolymer requires an appropriate composition design, e.g., by controlling the ratios of $\mathrm{Si} / \mathrm{Na}$ and/or $\mathrm{Si} / \mathrm{Al}$.

\section{Acknowledgement}

DY acknowledges the National Science Foundation of China (Nos. 51379186 and 51522905) and Research Center of Urban Resource Recycling Technology of Graduate School at Shenzhen, Tsinghua University and Shenzhen Green Eco-ManufacturerHigh-Tech Open Fund (No.URRT2013002). QZ acknowledges the National Natural Science Foundation of China (No. 51408536) and Fundamental Research Funds for the Central Universities (No.513210*172210251). The authors appreciate the efforts of the anonymous reviewers to improve the quality of this study.

[1] Provis JL, Bernal SA. Geopolymers and related alkali-activated materials. Annu Rev Mater Res 2014; 44:299327.

[2] NGouloure ZNM, Nait-Ali B, Zekeng S, Kamseu E, Melo UC, Smith D, Leonelli C. Recycled natural wastes in metakaolin based porous geopolymers for insulating applications. J Build Eng 2015;3:58-69.

[3] Provis JL. Geopolymer and other alkali activated materials: whyn how and what? Mater Struc 2014;47:11-25.

[4] Duxson P, Mallicoat SW, Lukey GC. The effect of alkali and Si/Al ratio on the development of mechanical properties of metakaolin-based geopolymers. Colloid Surface A 2007;292(1)8-20.

[5] Duxson P, Provis JL, Lukey GC, Mallicoat SW, Kriven WM, van Deventer JSJ. Understanding the relationship between geopolymer composition, microstructure and mechanical properties. Colloid Surface A 2005;269(13)47-58.

[6] van Deventer JSJ, Provis JL, Duxson P. Technical and commercial progress in the adoption of geopolymer cement. Miner Eng 2012;29:89-104. 
[7] McLellan BC, Williams RP, Lay J, van Riessen A, Corder GD. Costs and carbon emissions for geopolymer pastes in comparison to ordinary portland cement. J Clean Prod 2011;19:1080-1090.

[8] Turner LK, Collins FG. Carbon dioxide equivalent $\left(\mathrm{CO}_{2}\right.$-e) emissions: A comparison between geopolymer and OPC cement concrete. Constr Build Mater 2013;43:125-130.

[9] Salahuddin MMB, Norkhairunnisa M, Mustapha F. A review on thermophysical evaluation of alkali-activated geopolymers. Ceram Int 2015;41:4273-4281.

[10] Duan P, Yan C, Zhou W, Luo W, Shen C. An investigation of the microstructure and durability of a fluidized bed fly ash-metakaolin geopolymer after heat and acid exposure. Mater Design 2015;74:125-137.

[11] Roviello G, Menna C, Tarallo O, Ricciotti L, Ferone C, Colangelo F, Asprone D, Maggio R, Cappelletto E, Prota A, Cioffi R. Preparation, structure and properties of hybrid materials based on geopolymers and polysiloxanes. Mater Design 2015;87:82-94.

[12] Zhang Z, Provis JL, Reid A, Wang H. Geopolymer foam concrete: An emerging material for sustainable construction. Constr Build Mater 2014;56:113-127.

[13] Sarker PK, Kelly S, Yao Z. Effect of fire exposure on cracking, spalling and residual strength of fly ash geopolymer concrete. Mater Design 2014;63:584-592.

[14] Feng J, Zhang R, Gong L, Li Y, Cao W, Cheng X. Development of porous fly ash-based geopolymer with low thermal conductivity. Mater Design 2015;65:529-533.

[15] Nazari A, Riahi S, Bagheri A. Designing water resistant lightweight geopolymers produced from waste materials. Mater Design 2012;35:296-302.

[16] Ariffin MAM, Bhutta MAR, Hussin MW, Mohd Tahir M, Aziah N. Sulfuric acid resistance of blended ash geopolymer concrete. Constr Build Mater 2013;43:80-86.

[17] Medri V, Papa E, Mazzocchi M, Laghi L, Morganti M, Francisconi J, Landi E, Production and characterization of lightweight vermiculite/geopolymer-based panels. Mater Design 2015;85:266-274. 
[18] Huiskes DMA, Keulen A, Yu QL, Brouwers HJH. Design and performance evaluation of ultra-lightweight geopolymer concrete. Mater Design 2016;89:516-526.

[19] Islam A, Alengaram UJ, Jumaat MZ, Bashar II. The development of compressive strength of ground granulated blast furnace slag-palm oil fuel ash-fly ash based geopolymer mortar. Mater Design 2014;56:833-841.

[20] Posi P, Teerachanwit C, Tanutong C, Limkamoltip S, Lertnimoolchai S, Sata V, Chindaprasirt P. Lightweight geopolymer concrete containing aggregate from recycle lightweight block. Mater Design 2013;52:580-586.

[21] Zhang Z, Provis JL, Reid A, Wang H. Mechanical, thermal insulation, thermal resistance and acoustic absorption properties of geopolymer foam concrete. Cem Concr Compos 2015;62:97-105.

[22] Xu M, He Y, Wang C, He X, He X, Liu J, Cui X. Preparation and characterization of a self-supporting inorganic membrane based on metakaolin-based geopolymers. Appl Clay Sci 2015;115:254-259.

[23] Autef A, Joussein E, Poulesquen A, Gasgnier G, Pronier S, Sobrados I, Sanz J, Rossignol S. Influence of metakaolin purities on potassium geopolymer formulation: The existence of several networks. J Colloid Interface Sci 2013;408:43-53.

[24] Rowles M, O'Connor B. Chemical optimisation of the compressive strength of aluminosilicate geopolymers synthesised by sodium silicate activation of metakaolinite. J Mater Chem 2003;(13): 1161-1165.

[25] Cheng $\mathrm{H}$, Lin K, Cui R, Hwang C, Chang Y, Cheng T. The effects of $\mathrm{SiO}_{2} / \mathrm{Na}_{2} \mathrm{O}$ molar ratio on the characteristics of alkali-activated waste catalyst-metakaolin based geopolymers. Constr Build Mater 2015;95:710-720.

[26] Cheng H, Lin K, Cui R, Hwang C, Chang Y, Cheng T. Effect of solid-to-liquid ratios on the properties of waste catalyst-metakaolin based geopolymers. Constr Build Mater 2015;88:74-83.

[27] Gao K, Lin K, Wang D, Hwang C, Shiu H, Chang Y, Cheng T. Effects $\mathrm{SiO}_{2} / \mathrm{Na}_{2} \mathrm{O}$ molar ratio on mechanical properties and the microstructure of nano- $\mathrm{SiO}_{2}$ metakaolin-based geopolymers. Constr Build Mater 2014;53: $503-510$

[28] Wang H, Li H, Yan F. Synthesis and mechanical properties of metakaolinite-based geopolymer. Colloid Surf 2005;268:1-6. 
[29] Zhang Y, Sun W, Li Z. Composition design and microstructural characterization of calcined kaolin-based geopolymer cement. Appl Clay Sci 2010;47:271-275.

[30] Lizcano M, Kim HS, Basu S, Radovic M. Mechanical properties of sodium and potassium activated metakaolinbased geopolymers. J Mater Sci 2012;47:2607-2616.

[31] Wongpa J, Kiattikomol K, Jaturapitakkul C, Chindaprasirt P. Compressive strength, modulus of elasticity, and water permeability of inorganic polymer concrete. Mater Design 2010;31:4748-4754.

[32] Andini S, Cioffi R, Colangelo F, Grieco T, Montagnaro F, Santoro L. Coal fly ash as raw material for the manufacture of geopolymer-based products. Waste Manage 2008;28(2)416-423.

[33] Huang TC, Huang JS, Wang YW, Fan YC. Microstructure and properties of metakaolin-based inorganic polymer foams. J Mater Sci 2013;48(21): 7446-7455.

[34] Chen JH, Huang JS, Chang YW. Use of reservoir sludge as a partial replacement of metakaolin in the production of geopolymers. Cem Concr Compos 2011;33(5): 602-610.

[35] Metha PK, Monterio PJM. Concrete, Microstructure, Properties and Materials. London: McGraw-Hill, 2006.

[36] Rashad AM. Alkali-activated metakaolin: A short guide for civil Engineer - An overview. Constr Build Mater 2013;41:751-765.

[37] Pelisser F, Guerrino EL, Menger M, Michel MD, Labrincha JA. Micromechanical characterization of metakaolinbased geopolymers. Constr Build Mater 2013;49:547-553.

[38] Ozer I, Soyer-Uzun S. Relations between the structural characteristics and compressive strength in metakaolin based geopolymers with different molar Si/Al ratios. Ceram Int 2015;41:10192-10198.

[39] Barbosa VFF, MacKenzie KJD, Thaumaturgo C. Synthesis and characterisation of materials based on inorganic polymers of alumina and silica: sodium polysialate polymers. Int J Inorg Mater 2000;2309-317.

[40] Lyu Y, Hsiao Y, Wang T, Cheng T, Ueng T. Microstructure of geopolymer accounting for associated mechanical characteristics under various stress states. Cem Concr Res 2013;54:199-207. 
[41] Heah CY, Kamarudin H, Mustafa Al Bakri AM, Bnhussain M, Luqman M, Khairul Nizar I, Ruzaidi CM, Liew YM. Study on solids-to-liquid and alkaline activator ratios on kaolin-based geopolymers. Constr Build Mater 2012;35912-922.

[42] Sarker PK, Haque R, Ramgolam KV. Fracture behaviour of heat cured fly ash based geopolymer concrete. Mater Design 2013;44:580-586.

[43] He J, Zhang J, Yu Y, Zhang G. The strength and microstructure if two geopolymers derived from metakaolin and red mud-fly ash admixture: A comparative study. Constr Build Mater 2012;30:80-81.

[44] He J, Jie Y, Zhang J, Yu Y, Zhang G. Synthesis and characterization of red mud and rice husk ash-based geopolymer composites. Cem Concr Compos 2013; 37:108-118.

[45] Stefan L, Benboudjema F, Torrenti J, Bissonnette B. Prediction of elastic properties of cement pastes at early ages. Comp Mater Sci 2010;47:775-784

[46] Sanahuja J, Dormieux L, Chanvillard G. Modelling elasticity of a hydrating cement paste. Cem Concr Res $2007 ; 37: 1427-1439$

[47] Haecker CJ, Garboczi EJ, Bullard JW, Bohn RB, Sun Z, Shah SP, Voigt T. Modeling the linear elastic properties of Portland cement paste. Cem Concr Res 2005;35:1948-1960.

[48] Nasvi MMC, Gamage RP, Jay A. Geopolymer as well cement and the variation of its mechanical behavior with curing temperature. Greenhouse Gas Sci Technol 2012;2:46-58.

[49] Zeng, Q. Poromechanical behavior of cement-based materials subjected to freeze-thaw actions with salts. Doctoral dissertation, Université Paris-Est; 2011.

[50] Steven M, Sagoe-Crentsil K. Relationships between composition, structure and strength of inorganic polymers. J Mater Sci 2005;40(16): 4247-4259.

[51] Fisher R. Discussion of the analysis of variance with various binomial transformations. Biometrics. 1954;10(1)140-151. 
545

[52] Rovnanik P. Effect of curing temperature on the development of hard structure of metakaolin-based geopolymer. Constr Build Mater 2010;24(7)1176-1183.

[53] Mo B, He Z, Cui X, He Y, Gong S. Effect of curing temperature on geopolymerization of metakaolin-based geopolymers, Appl Clay Sci 2014;99:144-148. 


\section{Figure captions}

Figure 1: (a) Particle size distribution and (b) SEM photograph of the metakaolin powder.

Figure 2: Schematic illustration of the measurement system (left) and an in-situ picture of a specimen and apparatus under testing (right).

Figure 3: (a) Distribution of compressive strengths for the AE-grouped MKG pastes; (b) Distribution of compressive strengths for the Ms-grouped MKG pastes.

Figure 4: Typical mechanical behaviors of MKG paste under uniaxial compression: (a) stressstrain curves and (b) configurations of the different fracture states.

Figure 5: Stress-strain curves of the AS-grouped MKG specimens by (a) gauges and (b) LVDTs, and the Msgrouped MKG specimens by (c) gauges and (d) LVDTs.

Figure 6: Elastic properties of the AE-grouped MKG specimens: (a)Youngs modulus, (b) Poissons ratio, (c) Bulk modulus and (d) shear modulus.

Figure 7: SEM microstructures of (a) AE10, (b )AE30 and (c) AE50 MKG paste.

Figure 8: SEM-EDS results of (a) AE30 and (b) AE50 MKG pastes.

Figure 9: Elastic parameters of the Ms-grouped MKG specimens: (a)Youngs modulus, (b) Poissons ratio, (c) Bulk modulus and (d) shear modulus.

Figure 10: SEM-EDS results of the selected Ms-grouped MKG pastes: (a) Ms125, (b)Ms175 and (c) Ms225.

Figure 11: Quantitative correlations between the Youngs modulus and the AE dosage of the MKG pastes by the estimation formulation of Eq. (6). For comparison purpose, the experimental data in [4, 5, 30] were adopted.

Figure 12: Quantitative correlations between the Poissons ratio and the AE dosage of the MKG pastes by the estimation formulation of Eqn. 7. 